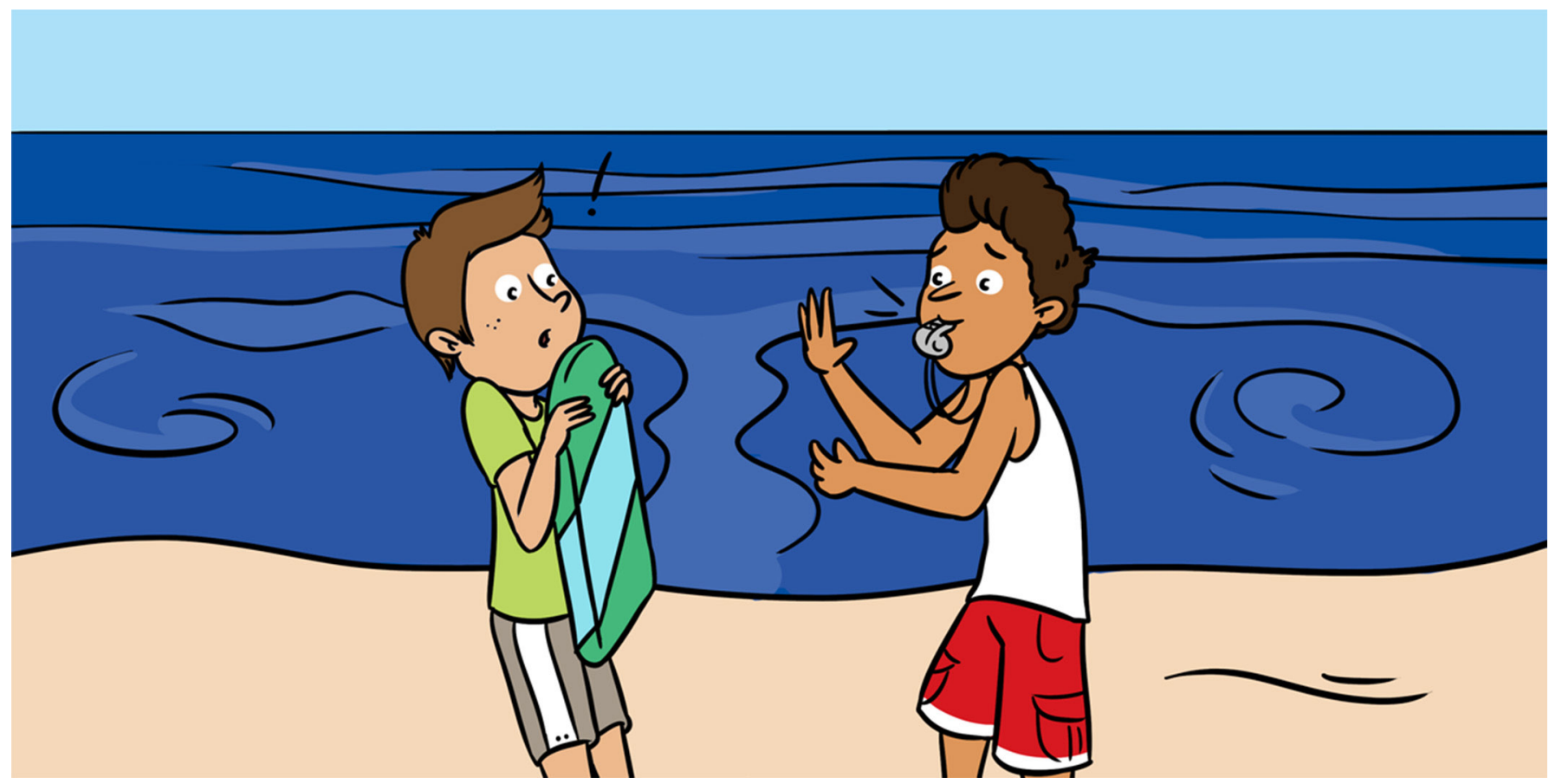

\title{
STAYING SAFE ON A SURF BEACH: WHAT ARE RIP CURRENTS?
}

\section{Sebastian J. Pitman ${ }^{1 *}$, Shari L. Gallop ${ }^{2,3}$ and Robert W. Brander ${ }^{4}$}

${ }^{1}$ Department of Geography, University of Canterbury, Christchurch, New Zealand

2 School of Science, Coastal Marine Field Station, University of Waikato, Tauranga, New Zealand

3 Department of Environmental Sciences, Macquarie University, Sydney, NSW, Australia

${ }^{4}$ School of Biological, Earth and Environmental Sciences, University of New South Wales Sydney, Sydney, NSW, Australia

YOUNG REVIEWERS:

NICOLAS

Everyone enjoys visiting the beach and playing or swimming in the water, but sometimes, waves breaking on beaches can create strong, narrow currents that can pull you out of your depth and into deeper water, where you may find yourself in trouble. We call these rip currents, and they are the main cause of drowning and rescues on surf beaches. The best way to stay safe at the beach is to always swim near lifeguards and avoid swimming if there are none around. Two important things to know about rip currents are: (1) how to spot them; and (2) what to do if you get caught in one. That is what we want to tell you about in this article!

\section{INTRODUCTION}

One of the fun things about the beach is watching and playing in the waves, which were likely made by wind hundreds of miles away. 


\section{Figure 1}

(A) An elevated view of a rip current, which can be seen as an area of calmer, darker water with no breaking waves. (B) A diagram of water circulation in a rip current, with dark arrows showing a rip current flowing through the deeper channel between sand bars. Photo credit: Rob Brander; diagram adapted from Surf Life Saving Australia.

\section{RIP CURRENT}

A strong offshore flow of water at the beach that is hazardous to people.

\section{SANDBAR}

Underwater mounds of sand that come in different shapes and sizes, often with deeper channels running through them.

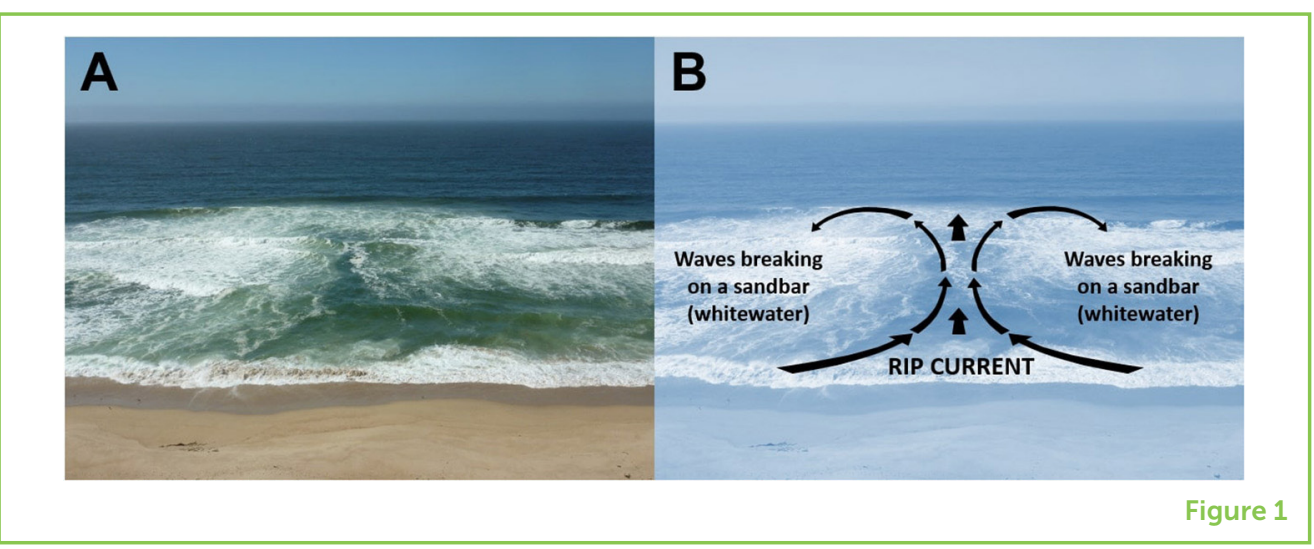

These waves travel long distances in deep water before they get to the beach. As the water gets shallower, the waves slow down and steepen, until they eventually topple over and "break." Breaking waves trap lots of air bubbles in the water, making the water look white and foamy, called whitewater. Most of this wave breaking occurs in an area called the surfzone-because this is where you can actually catch the waves and surf!

As the whitewater moves toward the beach, it does not just keep piling up at the beach (or else the whole beach would be underwater!), but instead, the water flows back offshore-thanks to strong, narrow currents called rip currents. While there are several different types of rip currents, most are just like rivers-they flow in deeper channels between shallow sandbars. Sandbars are underwater mounds of sand that come in different shapes and sizes, often with deeper channels running through them. Rips are formed by the action of breaking waves, and sand bars play an important role in this. Since waves mostly break in shallow areas, there is a lot of wave breaking and whitewater across sand bars, but not as much across the channels, where the water is deeper. This means that the easiest way for water to head back offshore is through the deeper channels and that is where most rip currents form [1]. Figure 1 shows what this water circulation pattern looks like. Not all beaches have rip currents, but if you see breaking waves (whitewater) across a wide surfzone, then there could be a rip.

\section{WHY ARE RIP CURRENTS DANGEROUS?}

Even in nice weather conditions, rip currents can flow offshore through these channels very quickly, sometimes at speeds of over $2 \mathrm{~m}$ (2.2 yards) a second, which is as fast as some Olympic swimmers! This means that even gentle rip currents can take swimmers of all abilities a long way offshore. A rip current can easily move someone the length of a football field in just $1 \mathrm{~min}$. What makes these currents dangerous is that you do 
not feel anything, you are just going with the flow. It is only when you realize that you are suddenly a long way from the safety of the beach that things get scary, and that is when most people start to panic. When people panic, they often try to swim back to the beach against the current and, in doing that, there is a risk they will use up all their energy.

There are many myths about rip currents. One is that a rip current is an "undertow" that will suck you under the water [2]. This myth makes people panic when they think they are caught in one-they do not want to be pulled under the water! However, scientific measurements show that rip currents would not pull you under [3]. Another myth is that rip currents will keep taking you offshore. That is also false-most rips take you out as far as the waves are breaking and sometimes some distance beyond, but they all stop eventually.

Unfortunately, it is very common for people to get caught in rip currents on beaches around the world and most rescues that beach lifeguards perform involve saving people caught in rips. This means that tens of thousands of people are caught in rip currents every year. If it was not for the lifeguards, the number of drownings would be terrible. So, why are so many people getting in trouble in rip currents? Because they either did not swim near lifeguards, did not know how to spot a rip current, or did not even know what a rip current was, or how it worked.

\section{HOW DO I AVOID RIP CURRENTS?}

The best way to avoid getting caught in a rip current is learning to avoid them. As mentioned before, the best way to stay safe is to always swim near a lifeguard, or in areas designated safe for swimming by lifeguards. In countries like Australia, New Zealand, and the UK, safe areas are

Figure 2

(A) The best way to avoid rip currents is to swim in an area with lifeguards, such as between the pair of red and yellow flags on this New Zealand beach (photo: Jodie Wilson) (B) You should always check for warning signs like this one on a beach in the United States and read them if present (courtesy: NOAA).

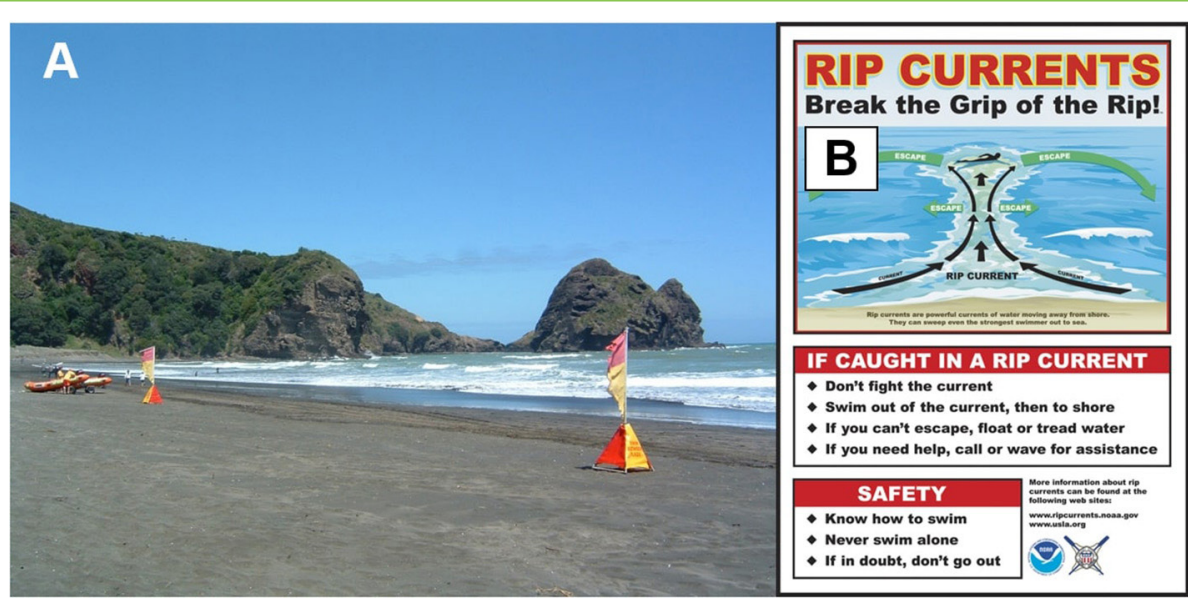

Figure 2 
Figure 3

Some examples of rip currents showing different visual clues on how to spot them

$(A, B)$ You should look for the deeper, darker, and calmer water that indicates where a rip current might be. The current is usually surrounded either side by whitewater and breaking waves (photos: Jamie Shulmeister and Seb Pitman). (C) There are multiple rip currents visible in this photo taken at Perranporth Beach (England). How many can you spot? (photo: Seb Pitman) (D) Sometimes, rip currents also pick up lots of sediment and you can see it traveling offshore in the water (photo: Los Angeles Fire Department). marked by a pair of red and yellow flags and the rule is "always swim between the flags" (Figure 2). Other countries have lifeguards spread out along the beach and have different colored flags relating to the safety level, such as in the United States, where a red flag means dangerous conditions and a green one means safe swimming conditions.

However, lifeguards are not always present. In that case, you should always follow the rule "if in doubt, do not go out," or never go deeper than waist-depth, particularly if you are a poor swimmer. Always keep your feet firmly on the sand.

Some beaches may have warning signs about hazards, such as rip currents. You should always have a look at the signs at a beach, as they may indicate the location of a rip current or notify you of other hazards. If there are no lifeguards or signs and you still want to go swimming (not recommended!), you must keep in mind that there may be rip currents present. In that case, knowing how to spot them is very important.

Rip currents can be a little tricky to spot unless you know what to look for. Rip currents tend to look different from the surrounding water. Remember earlier we said that rip currents occur in deep channels where there are no waves breaking? That is the first clue as to how we can spot these currents. Look for areas of water where waves are not breaking - particularly narrow gaps of darker, calmer-looking water extending offshore. That could be a rip current, and good examples are shown in Figure 3. Because rip currents look calm, many people think they look like the safest place to swim and often choose to enter the water right in the middle of the rip current! As rip currents carry water offshore and waves bring water toward the shore, there is often some interference, and the surface of the water where there is a rip current

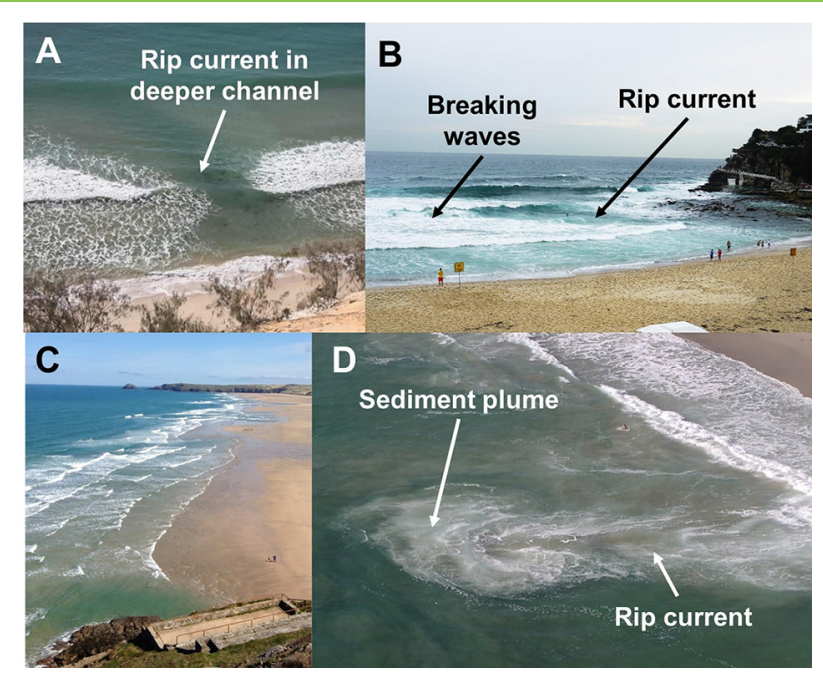

Figure 3 
may look bumpy or have a different texture than the surrounding water. Rips also carry floating debris, like foam and clouds of sand, offshore (Figure 3D). These visual clues are sometimes hard to identify, so you need to spend several minutes watching the water for any of these tell-tale signs of rip currents.

\section{WHAT TO DO IF YOU ARE CAUGHT IN A RIP CURRENT!}

If you think you are caught in a rip current, try to relax and remember that the rip is not going to pull you under the water; it is just taking you for a ride. If you are on a beach with lifeguards, raise an arm in the air to signal for help while treading water. The lifeguards will see this and know to come and get you, and you might even attract the attention of other swimmers or surfers in the area who can help you out. Some research has shown that, often, rip currents will eventually bring you back toward the shore [4], so just keep floating and save your energy.

If you really think you are not heading back to shore, and you have not attracted anyone's attention, it is very important to remember that not even Olympic swimmers can outswim a rip current, so do not try to swim straight back to shore against the current. Instead, try to work out which direction the rip current is taking you and swim slowly, but steadily, across the rip to one side and aim for areas of whitewater. Rip currents are generally no wider than about $15 \mathrm{~m}$ (16.4 yards), so you only need to swim a short distance to try and get out of the current. Once out of it, you should be able to stand up and make your way back to shore in the areas where you can see breaking waves.

This is just a quick overview of how to spot and escape rip currents. There are several good sources of information where you can learn even more about rip currents. ${ }^{1}$

\section{CONCLUSION}

Rip currents are dangerous, offshore flows of water found at beaches where waves break across a surfzone and these currents responsible for many people getting into trouble while swimming. Rip currents often occur in deeper channels, between areas of breaking waves, and can

\footnotetext{
${ }_{1}^{1}$ National Oceanic and Atmospheric (NOAA) Rip Current Science Resource: https://www.weather.gov/safety/ripcurrent-science

Beachsafe-Surf Life Saving Australia: https://beachsafe.org.au/surf-safety/ripcurrents Science of the Surf: http://www.scienceofthesurf.com

RNLI DRIBs (UK): http://www.ripcurrents.co.uk/
} 
flow at speeds up to $2 \mathrm{~m} / \mathrm{s}$. It is really important that you use the skills you learned in this article to try to spot rip currents, so you can avoid them at the beach. You can look for patches of calm water between breaking waves, or the offshore movement of debris and sediment. If you are caught in a rip current, relax, float, and remember that it would not pull you under the water. Instead, you can raise your arm to signal for help, stay afloat, and slowly swim toward the breaking waves on either side of the current to help you get back to shore. Of course, the best way to stay safe at the beach is to always swim near a lifeguard!

\section{REFERENCES}

1. Castelle, B., Scott, T., Brander, R. W., and McCarroll, R. J. 2016. Rip current types, circulation and hazard. Earth Sci. Rev. 163:1-21. doi: 10.1016/j.earscirev. 2016.09.008

2. Gallop, S. L., Woodward, E., Brander, R. W., and Pitman, S. J. 2016. Perceptions of rip current myths from the central south coast of England. Ocean Coast. Manage. 119:14-20. doi: 10.1016/j.ocecoaman.2015.09.010

3. MacMahan, J., Brown, J., Brown, J., Thornton, E., Reniers, A., Stanton, T., et al. 2010. Mean Lagrangian flow behavior on an open coast rip-channeled beach: a new perspective. Mar. Geol. 268:1-15. doi: 10.1016/j.margeo.2009.09.011

4. Pitman, S., Gallop, S. L., Haigh, I. D., Masselink, G., and Ranasinghe, R. 2016. Wave breaking patterns control rip current flow regimes and surfzone retention. Mar. Geol. 382:176-90. doi: 10.1016/j.margeo.2016.10.016

SUBMITTED: 27 September 2018; ACCEPTED: 14 February 2019; PUBLISHED ONLINE: 06 March 2019.

EDITED BY: Dominik K. Großkinsky, University of Copenhagen, Denmark

CITATION: Pitman SJ, Gallop SL and Brander RW (2019) Staying Safe on a Surf Beach: What Are Rip Currents? Front. Young Minds 7:33. doi: 10.3389/frym.2019.00033

CONFLICT OF INTEREST STATEMENT: The authors declare that the research was conducted in the absence of any commercial or financial relationships that could be construed as a potential conflict of interest.

COPYRIGHT () 2019 Pitman, Gallop and Brander. This is an open-access article distributed under the terms of the Creative Commons Attribution License (CC BY). The use, distribution or reproduction in other forums is permitted, provided the original author(s) and the copyright owner(s) are credited and that the original publication in this journal is cited, in accordance with accepted academic practice. No use, distribution or reproduction is permitted which does not comply with these terms. 


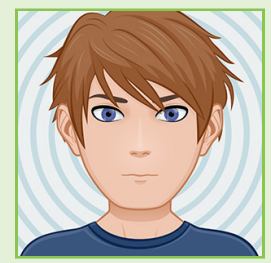

\section{YOUNG REVIEWERS}

\section{NOAH, AGE: 13}

My name is Noah. I enjoy scalloping and snorkeling with my family. My favorite subject in school is science. My three brothers and I like to play video games together. I enjoy cold weather the most and love traveling to the mountains. We have a Shiba Inu dog named Cody. He likes to smile and knows several tricks. When I grow up I want to be in the medical field, maybe working as an X-ray technician.

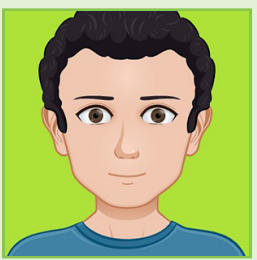

\section{NICOLAS, AGE: 8}

Hello, my name is Nicolas and I am 8 years old. I was born in England, but I moved to Madrid (Spain) when I was 1 and now I live in Vienna (Austria). So I speak English, Spanish, and German.

\section{AUTHORS}
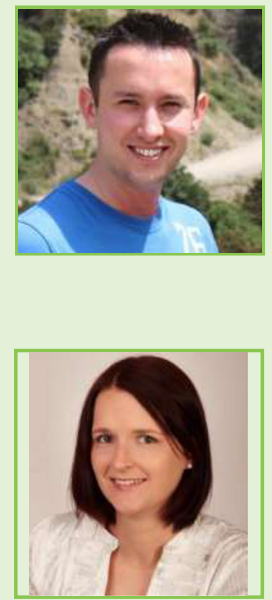

\section{SEBASTIAN J. PITMAN}

I am a Lecturer at the University of Canterbury in New Zealand. My research focuses on measuring rip currents with a combination of techniques, including field experiments and the use of video cameras to record the rip currents. I am currently working closely with Surf Lifesaving New Zealand, to better predict rip currents on surf beaches in the North of the country. *sebastian.pitman@ canterbury.ac.nz

\section{SHARI L. GALLOP}

I am a Physical Marine Scientist. My research aims to understand relationships between the ocean and coast, over different scales of time and space. I have done extensive research on surf zones, rip current circulation, and safety implications. I am a Senior Lecturer at the University of Waikato, Tauranga, New Zealand.

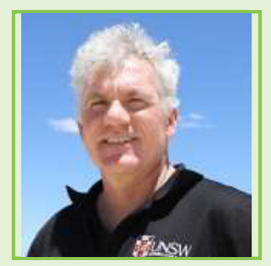

\section{ROBERT W. BRANDER}

I am a Coastal Geomorphologist (someone who studies how the coast changes) and beach safety scientist from UNSW Sydney. My research is focused on the physical characteristics of beach hazards, such as rip currents, and applying social science methods to both understanding and improving beachgoer behavior in regards to beach hazards. 